\title{
Improved outcomes following a single session web-based intervention for problem gambling
}

\author{
Rodda, S.N., ${ }^{1,2,3,4}$ Lubman, D. I., ${ }^{1,2}$ Jackson, A.C. ${ }^{5}$ \& Dowling, N. A ${ }^{3,5,6}$ \\ 1Turning Point, Eastern Health, Australia \\ 2Eastern Health Clinical School, Monash University, Australia \\ 3 School of Psychology, Deakin University, Australia \\ 4 Auckland University of Technology, New Zealand \\ 5University of Melbourne, Carlton, Victoria, Australia \\ 6 School of Psychology and Psychiatry, Monash University, Australia
}

Keywords: online, session evaluation; gambling; single session; web-based counselling; satisfaction

\author{
Corresponding author \\ Dr Simone Rodda \\ Lecturer \\ School of Public Health and Psychosocial Studies \\ 90 Akoranga Drive I Private Bag 92006 I Auckland 1142 \\ New Zealand T: +64 99219999 ext. 8120 \\ simone.rodda@aut.ac.nz
}

Research suggests online interventions can have immediate impacts, however this is yet to be tested with help-seeking adults and in particular those with problem gambling. The current study involved 229 participants classified as problem gamblers who accessed Gambling Help Online between November 2010 and February 2012. Almost half were aged under 35 years of age (45\%), male (57\%) as well as first time treatment seekers $(62 \%)$. Following the provision of a single-session of counselling, participants completed ratings of session evaluation (depth and smoothness), readiness to change and level of psychological distress. Pre- and post-session evaluation analyses indicated a significant increase in confidence and a significant decrease in distress with moderate effect sizes $(\mathrm{d}=$ .56 and .63 respectively). A hierarchical regression found that the session evaluation was a significant predictor of change in confidence, however only the sub-scale smoothness was a significant predictor of change in distress. This was the case even after controlling for pre-session distress, session word count and client characteristics (gender, age, preferred gambling activity, preferred mode of gambling, gambling severity, and preferred mode of help seeking). This exploratory study is the first to examine the impact of single session, immediate, web-based counselling for problem gambling and has significant implications for clinical training as well as delivery of interventions.

\section{Acknowledgments}

The authors would like to acknowledge the efforts by states and territories in forming a collaborative funding agreement for Gambling Help Online and in particular the Victorian Responsible Gambling Foundation as contract managers. In addition, the first author was funded by an Australian Postgraduate Award and we would like to thank Kathleen Bagot for her assistance with data analysis. Lastly, we would also like to thank all the counsellors involved in providing the Gambling Help Online service as well as the willingness of people affected by problem gambling to access this new modality. 
Web-based intervention for problem gambling 1

\section{Improved outcomes following a single session web-based intervention for problem gambling}

Research suggests online interventions can have immediate impacts, however this is yet to be tested with helpseeking adults and in particular those with problem gambling. The current study involved 229 participants classified as problem gamblers who accessed Gambling Help Online between November 2010 and February 2012. Almost half were aged under 35 years of age $(45 \%)$, male $(57 \%)$ as well as first time treatment seekers $(62 \%)$. Following the provision of a single-session of counselling, participants completed ratings of session evaluation (the degree of depth and smoothness), readiness to change and level of psychological distress. Pre- and postsession evaluation analyses indicated a significant increase in confidence and a significant decrease in distress with moderate effect sizes $(\mathrm{d}=.56$ and .63 respectively). A hierarchical regression found that the session evaluation was a significant predictor of change in confidence, however only the sub-scale smoothness was a significant predictor of change in distress. This was the case even after controlling for pre-session distress, session word count and client characteristics (gender, age, preferred gambling activity, preferred mode of gambling, gambling severity, and preferred mode of help seeking). This exploratory study is the first to examine the impact of single session, immediate, web-based counselling for problem gambling and has significant implications for clinical training as well as delivery of interventions.

A wide range of options across a range of modalities are available for the treatment of problem gambling. Over the past 20 years, cognitive behavioural and motivational therapies have emerged with the strongest evidence (Cowlishaw et al., 2012) and have been recommended in practice guidelines (Thomas et al., 2011). Although much of the research used for practice guidelines has been with face-to-face populations, there is now growing evidence that even the most minimal contact with a professional can affect change in gambling outcomes. Indeed, single session interventions have been shown to be as effective as more intense interventions that are longer in duration (e.g., 6 sessions delivered over 8-10 weeks) (Petry, Weinstock, Ledgerwood, \& Morasco, 2008; Toneatto \& Gunaratne, 2009) and/or include more content (e.g., addition of workbook) (Abbott et al., 2012). However, outcomes involving practitioner contact appear better than a workbook alone (Hodgins, Currie, el-Guebaly, \& Peden, 2004; Hodgins, Currie, Currie, \& Fick, 2009; Thomas et al., 2011). Almost all of these brief interventions involve the delivery of motivational enhancement aimed at increasing readiness to change and/or the delivery of advice or information.

With the exception of Abbott et al. (2012), most research on the impact of single session interventions for problem gambling has involved participants recruited and treated in university or academic settings. In community settings, most single session interventions are delivered by telephone or, more recently, online services. Indeed, there has been enormous growth in the delivery of online services which provide single points of contact (King, Bickman, Shochet, McDermott, \& Bor, 2010). In the area of problem gambling, web-based counselling options are considered particularly important, as less than $10 \%$ of individuals affected by problem gambling attend traditional problem gambling services (Productivity Commission, 2010). Barriers to treatment 
include pride and denial with shame and stigma identified as key issues (Gainsbury, Hing, \& Suhonen, 2013;

Suurvali, Cordingley, Hodgins, \& Cunningham, 2009). Importantly, web-based counselling has been found to attract a high rate of new treatment seekers (Dowling, Rodda, Lubman, \& Jackson, 2014; Rodda \& Lubman, 2012; Rodda, Lubman, Dowling, Bough, \& Jackson, 2013; Rodda, Lubman, Dowling, \& McCann, 2013) and is considered by clients to provide easy and convenient access, anonymity and opportunities for discrete contact with a health professional (King, Bambling, Lloyd, et al., 2006; Rodda, Lubman, Dowling, Bough, et al., 2013; Rodda, Lubman, Dowling, \& McCann, 2013; Wood \& Griffiths, 2007). Of the range of interventions delivered over the internet (e.g., self-directed, self-assessment), web-based counselling most approximates a therapeutic exchange in that it is synchronous and involves an exchange between a client and professional. In addition, webbased counselling is entirely text based and is often offered without appointment or wait time. The client typically contacts a service when the need arises and can maintain contact for as little or as long as is helpful. Although the number of words that can be spoken is around half that of an oral conversation, counselling sessions are typically around 50 minutes in duration (Rodda \& Lubman, 2012).

Web-based counselling has provided help to thousands of gamblers internationally. It has been offered for problem gambling for more than 10 years in the UK and since 2009 in Australia. There is little available information, however, about its impact on problem gambling. This lack of research reflects the limited evidence base for other disorders. A recent systematic review found that only six studies have sought to measure the effectiveness of online chat for any issue, such as depression, work place issues, anxiety and general support (Dowling \& Rickwood, 2013). Four of these studies involved a single session of chat, all of which conducted evaluations prior to and following the web-based session. Only one study conducted a longer-term follow-up (onemonth) evaluation. The systematic review concluded that online chat was effective in all of these studies, as determined by reductions in distress and perceived burden, as well as improvements in well-being and global functioning.

Much of the process research on how web-based counselling works has focussed on the therapeutic alliance within ongoing, appointment-based web-based counselling rather than single sessions of counselling. However, King, Bambling, Reid, and Thomas (2006) identified that measures of the character of the sessions were better predictors of positive outcomes associated with online chat than measures examining therapeutic alliance. They proposed that the characteristics of web-based counselling (i.e., absence of visual or aural cues) are more associated with therapeutic tasks rather than establishing a relationship. Subsequent web-based research has adopted this measurement approach, administering the Session Evaluation Questionnaire (SEQ), which focuses 
on the character of sessions (Barak \& Bloch, 2006; Bewick, 2010; Reynolds, Stiles, Bailer, \& Hughes, 2013;

Reynolds, Stiles, \& Grohol, 2006). This questionnaire requires the respondent to rate a single session by depth (versus shallow) and smoothness (versus bumpy) (Stiles \& Snow, 1984). Ratings of session depth aim to measure perceived value, fullness and power of sessions in addition to whether the session is perceived as special (versus ordinary). In contrast, session smoothness is evaluated by ease of progress (e.g., smooth sailing), with smooth sessions characterised as relaxed, pleasant, comfortable and easy. Friedlander, Thibodeau, and Ward (1985) suggest a good session is characterised by SEQ scores above the median of the range of possible scores (i.e., 3.5). Specifically, good sessions are those in which the scores of counsellors are above the median on depth and in which clients score above the median on smoothness. In addition, sessions scored as poor typically involved the client talking more than the counsellor and in which the counsellor was either under involved (low level of encouragement or reflection) or tended towards providing advice. These 'rules' are important in that they have been shown to predict client drop out from face-to-face treatment (Samstag, Batchelder, Muran, Safran, \& Winston, 1998; Tryon, 1990) increased intention to seek professional help following the single session (Wade, Post, Cornish, Vogel, \& Tucker, 2011). Clients engaged in boing ongoing and single session web-based counselling have consistently rated sessions as deep and as smooth as other modalities such as face-to-face (Cohen \& Kerr, 1998; Reynolds et al., 2013). This, however, has yet to be demonstrated with people seeking help for problem gambling.

Recommended measurement of the treatment outcomes for problem gambling such as "The Banff Consensus" typically include gambling time and money spent, problem gambling severity, and associated problems such as psychological distress, substance use and general well-being over longer follow-up periods (Cowlishaw et al., 2012; Thomas et al., 2011; Walker et al., 2006). With the exception of psychological distress, these measures have limited utility in populations that are anonymous and engaged in just one session. Psychological distress (including state depression and anxiety) is often measured in treatment outcome studies for problem gambling in face-to-face (Christensen et al., 2013; de Lisle, Dowling, \& Allen, 2014; Dowling, Smith, \& Thomas, 2006, 2007, 2009; Riley, Smith, \& Oakes, 2011) and telephone modalities (Rodda \& Lubman, 2012). However, distress is typically measured as 'over the past week' or 'month' rather than presenting levels of distress. This is despite research suggesting gamblers seek help in response to a crisis or distressing episode of gambling (Blaszczynski \& Nower, 2002; Evans \& Delfabbro, 2005; Gainsbury et al., 2013) and that treatment-seeking problem gamblers report high rates of mental health disorders (Dowling et al., in press; Dowling et al., in press). 
In addition to improvements in gambling involvement and associated harms, the Banff Consensus

recommends the measurement of factors that theoretically change as a result of a particular intervention (e.g., motivational enhancement, cognitive behavioural therapy), such as readiness to change or beliefs about chance. While helplines and indeed online services do not typically adhere to a specific theoretical perspective, an important outcome is enhancement to levels of readiness either to change or engage in further help-seeking (Urbis, Keys and, \& Young., 2003). In terms of problem gambling, readiness as an outcome is rarely reported. However, readiness at baseline predicts longer term outcomes (Ledgerwood, Wiedemann, Moore, \& Arfken, 2011; Petry, 2005; Wohl \& Sztainert, 2011; Wulfert, Blanchard, Freidenberg, \& Martell, 2006) and strength of commitment to change (Hodgins, Ching, \& McEwen, 2009). There is also some evidence that a range of demographic and gambling variables including age, gender as well as gambling type, mode and severity (Ledgerwood et al., 2013; Petry, 2005) are related to a client's readiness to change. Research investigating readiness to change in a large sample of online help seekers reported that most gamblers were ready to make a change but had low confidence to resist an urge to gamble (Rodda, Lubman, Iyer, Gao, \& Dowling (2015).

Similar demographic and gambling variables have been employed to predict treatment attrition and outcome in an effort to improve the effectiveness of clinical interventions for problem gambling. Although the evidence base for demographic factors, such as gender and age, provides mixed findings (Crisp, Thomas, Jackson, \& Thomason, 2001; Dowling et al., 2009; Dowling, 2013; Guo et al., 2012; Melville, Casey, \& Kavanagh, 2007 ; Smith, Thomas, \& Jackson, 2004), there is more consistent evidence that greater gambling severity at pretreatment evaluations is associated with poorer treatment outcomes (Crisp et al., 2001; Dowling, 2013; Guo et al., 2012; Smith et al., 2004).

We expect that for at least some clients, a single session of web-based counselling will lead to positive change. However, we have little knowledge of whether change is related to the person, the character of intervention or just the act of accessing help. The current study aimed to address this gap in the literature by evaluating the impact of web-based counselling for problem gambling. Specifically, it was hypothesised that (1) web-based counselling will be associated with an increase in readiness to change (improvement, readiness, and confidence) and a reduction in psychological distress; (2) client characteristics (gender, age, preferred gambling activity, preferred mode of gambling, gambling severity, and preferred mode of help seeking) and session evaluation (depth and smoothness) will be associated with an improvement in readiness to change and a decrease in psychological distress and (3) session evaluation will predict improvement in readiness to change and psychological distress over and above client characteristics. 


\section{Method}

\section{Participants}

The current study recruited a sample of 235 gamblers who accessed web-based counselling (chat) offered by the Australian online gambling service, Gambling Help Online between November 2010 and February 2012. Six participants had more than $50 \%$ missing data and were removed from the analysis. As data collection involved forced data entry, missing data indicated technical problems and as such the entire participant was removed from the analysis leaving a sample of 229 participants. Participants included 130 males (56.8\%) and 99 females (43.2\%). The sample was split at 35 years reflecting expected familiarity with technology and included 104 participants under 35 years $(45.4 \%)$ and 125 participants 35 years of age or older (54.6\%). Participants were most often engaged in non-strategic gambling (such as electronic gaming machines [EGMs], lotteries, bingo, and keno) (70.3\%) than strategic gambling (such as wagering, casino gambling, and sports betting), with $21.4 \%$ preferring to gamble online or via the telephone. All participants were classified within the problem gambling category on the Problem Gambling Severity Index (PGSI) of the Canadian Problem Gambling Index (Ferris \& Wynne, 2001) $(M=21.6, S D=4.0)$. Almost two-thirds of participants were seeking help for gambling problems for the first time $(62.4 \%)$

Gambling Help Online offers immediate, 24/7 free counselling, information and support to anyone affected by problem gambling. Staffed by professional counsellors with backgrounds in psychology and social work, the service is entirely text based and offered without an appointment. Sessions had an average duration of 53 minutes $(S D=22.8$, range 13-126 minutes, median=53 minutes) and contained an average of 53 lines of text ( $S D=37.3$, range 8-328 lines, median=43 lines). Similar to previous research involving email counselling (Ledbetter \& Larson, 2008), the diversity in the range of lines and time spent per session was accounted for by calculating the total number of words in the transcript as a means of accounting for speed of typing, number of lines and duration. The mean number of words per session was 1133 ( $S D=561.5$, range 180-2978 words, median=1065 words).

\section{Materials}

Client characteristics included gender, age, preferred gambling activity (strategic or non-strategic), preferred mode of gambling (i.e., face-to-face, telephone, online) and preferred mode of help-seeking. Gambling severity was measured with the PGSI, which is the most frequently used screen for problem gambling (Postel, 
2010). Respondents are asked to indicate how often each item applied to them in the previous 12 months on a 4 point scale. Scores range from 0 to 27 , where higher scores indicate greater problem severity. Scores of 8 or higher on the PGSI indicate problem gambling. The PGSI has good internal consistency, test-retest reliability and criterion validity with measures of gambling involvement (Ferris \& Wynne, 2001). The internal consistency reliability of this scale in the current study was good $(\alpha=.77)$.

Readiness to change was measured with a set of three readiness rulers that were adapted for problem gambling. These included importance, readiness, and confidence. Originally developed by Miller and Rollnick (2002), readiness rulers are increasingly becoming used in clinical practice as well as research to measure readiness to change. These rulers were selected due to their brevity and good psychometric properties. A recent psychometric studies on the specific rulers of readiness, importance and confidence found the three constructs correlated highly, demonstrated high convergent validity with the stages of change model, and had good predictive validity for actual changes to drug, alcohol and tobacco use (Abar, Baumann, Rosenbaum, Boyer, \& Boudreaux, 2012; Abar et al., 2013; Boudreaux et al., 2012; Hesse, 2006). Specifically, participants indicated on a scale of 1 to 10 'how important is it for you that you limit/stop your gambling' (importance), 'where does losing limiting/stopping gambling fit on your list of priorities?' (readiness), and 'how confident are you that you could deal with an unexpected urge to gamble?' (confidence).

Psychological distress was measured with one item from the Positive and Negative Mood States (PANAS: MacKinnon et al., 1998). Specifically, we asked participants to indicate 'on a scale of 1 to 10,1 being not distressed at all and 10 being very distressed, right now how distressed are you?'

Session depth and smoothness was measured with the 11-item Session Evaluation Questionnaire (SEQ: Stiles \& Snow, 1984), which evaluates the depth (versus shallowness) and smoothness (versus bumpiness) of counselling session. While the SEQ was primarily developed as an evaluation of face-to-face ongoing counselling sessions, it has now been used in multiple process studies of web-based counselling: email interactions (Reynolds et al., 2006), single session synchronous chat (Barak \& Bloch, 2006; Cohen \& Kerr, 1998), and comparisons between chat and email counselling (Reynolds et al., 2013).

Compared to other rating scales, the scale items are more concerned with the session process rather than the therapeutic relationship. The SEQ includes two sub-scales of 5 items each with a 7-point Likert scale between polar adjectives: depth (valuable-worthless, deep-shallow, full-empty, weak-powerful and special-ordinary) and smoothness (easy-difficult, relaxed-tense, pleasant-unpleasant, smooth-rough and comfortable-uncomfortable). In addition, it has a single item (good-bad) using the same response scale that has been used as a global evaluation 
( 1 indicating bad and 7 indicating good). There are calculated means and ranges established from nine face-toface studies for depth $($ median $=5.2$, range $=4.7-5.9)$ and smoothness (median $M=4.4$, range $=4.1-5.3)($ Reynolds Jr et al., 2013). In Reynolds and colleagues own web-based counselling study, the SEQ subscales had high internal consistencies ( $\alpha=.94$ for depth and $\alpha=.92$ for smoothness) and means were higher for web-based counselling than face-to-face counselling for both session depth $(M=5.5, S D=1.5)$ and smoothness $(M=4.8, S D=1.7)$. Chronbach's alpha for the current study was good for both depth $(\alpha=.88)$ and smoothness $(\alpha=.84)$.

In the current study, the two sub-scales from the SEQ were rated on smoothness $(M=5.2, S D=1.3)$ and depth $(M=4.7, S D=1.4)$, with the overall good-bad item rated as $M=5.8(S D=1.7)$. As indicated in Table 1 , the highest items were ratings of the online session as pleasant and easy and the lowest average score was on the item that measured the specialness of the session. All scores were above a median of 3.5 indicating they can be classified as "good” sessions (Friedlander et al., 1985).

Insert Table 1 about here

\section{Procedure}

Ethics approval was granted from the University of Melbourne's Human Research Ethics Committee (ID: 1034028) and the Department of Justice's Human Research Ethics Committee (JHREC) (CF/10/17108). Participants completed a web-based counselling session offered through the Australian online counselling and support program, Gambling Help Online. Participants completed the client characteristic (including gambling severity), readiness to change, and psychological distress questionnaires prior to the counselling session and were asked to complete some measures (i.e., readiness to change, psychological distress, and session depth and smoothness) via a link when closing the session. While pre-session data was mandatory and part of the standard registration process, the post-session survey was optional. The post-session survey was approximately 10 minutes in duration and had a response rate of $17 \%$. This rate reflects all eligible service users and excluded those who were family and friends or not people with a gambling problem. While this response rate is low, we did not promote or push the survey to the client. Other research involving single session clients in face-to-face settings has found a similar response rate of $22 \%$ (Miller, 2008).

\section{Data analysis}


Data was analysed using SPSS 22. The impact of web-based counselling was evaluated using a series of repeated

measures t-tests. Because only confidence and psychological distress displayed significant improvement, the remainder of the analyses were conducted using these variables. To test the association between improvement in confidence and psychological distress and client characteristics, session evaluation, partial correlations were conducted controlling for pre-session confidence and distress. Pre-session confidence was controlled for when examining relationships involving post-session confidence and pre-session distress was controlled for when examining relationships involving post-session distress. In addition, both pre-session confidence and distress were controlled when examining the relationship between post-session confidence and distress. To determine whether depth and smoothness would predict improvement in confidence and distress over and above client characteristics, a series of regression analyses were conducted. Prior to conducting the regression analyses, tests for relevant assumptions were conducted. To control for the broad range in session duration, number of words and session duration were included in subsequent analyses. These were highly correlated in both regressions (i.e., .80). Although collinearity statistics (i.e., Tolerance and VIF) indicated that that it was within accepted limits, session duration was removed and the number of words retained on the assumption that it was a better indicator of the session "length" than duration (due in part to typing speed of both participant and counsellor). In addition, Mahalanobis distance scores indicated multivariate outliers. One outlier was identified, related to the participant's number of words. In this case, the participant was retained but the number of words was removed. No other outliers were identified and residual and scatter plots indicated the assumptions of normality, linearity and homoscedasticity were all satisfied (van Wier et al., 2009). In addition to controlling for the length of the session, when analysing change in readiness to change and psychological distress, we controlled for individual differences in pre-session scores. This method of analysis assists with overcoming the regression to the mean effect (Bland \& Altman, 1994; Bonate, 2010). As recommended by Hosmer and Lemeshow (1989) potential predictor variables were included in the regressions based on a liberate criterion for significance with post-confidence and post-

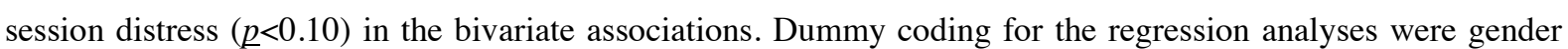
$(0=$ male, $1=$ female $)$, age $(0=<35$ years, $1=>35$ years $)$, preferred gambling activity $($ strategic $=0$, non-strategic $=1)$, preferred mode of gambling $(0=$ online/phone, $1=$ face-to-face). Continuous variables included number of words (180-2978), gambling severity $(0-27)$, readiness to change $(1=$ low-10 $=$ high $)$, psychological distress $(1=$ low$10=$ high), preferred mode of help-seeking (1-10), session smoothness (1-7), and session depth (1-7).

\section{Results}




\section{Impact of web-based counselling}

Participants rated their pre-session readiness to change highly in terms of importance $(M=9.4, S D=1.3)$ and readiness $(M=9.2, S D=1.6)$. Each of these scores increased from the pre- to post-session evaluation $(M=9.6$ $S D=1.3, d=.05$, and $M=9.3, S D=1.5, d=.09$ respectively), but these increases were not statistically significant (importance, $t(228)=1.4, p=.17$, and readiness, $t(228)=1.4, p=.16)$. In contrast, low levels of confidence to resist an urge to gamble were reported at session commencement $(M=4.1, S D=2.7)$. Following the intervention, confidence increased significantly by an average of $1.5(t(228)=-9.4 p<.001)$, with a medium effect size of $d=0.56$. As shown in Figure 1, participants also indicated high levels of psychological distress at the pre-session evaluation $(M=7.2, S D=2.7)$, which also significantly decreased at the post-session evaluation $(M=6.0, S D=2.9)$ $(t(229)=7.0, p<.001)$, with a medium effect size of $d=0.63$.

Insert Figure 1 about here

\section{Association between improvement in readiness and psychological distress with client characteristics and session evaluation}

A series of partial correlations explored the associations between session outcomes (confidence and psychological distress), client characteristics (gender, age, preferred gambling activity, preferred mode of gambling, gambling severity, and preferred mode of help-seeking), and session evaluation (depth and smoothness). As shown in Table 2, post-session confidence and post-session distress were strongly correlated. In addition, post-session confidence was significantly related to session depth and smoothness, as well as being under 35 years of age and a preference for online help seeking. Post-session distress was significantly associated with session depth and smoothness, betting in venues as well as a preference for online help-seeking.

Insert Table 2 about here

\section{Prediction of improved confidence and psychological distress over and above client characteristics}

A hierarchical multiple regression analysis was used to test if the character of the web-based intervention (depth and smoothness) predicted post-session ratings of confidence and psychological distress above and beyond client characteristics. A three stage hierarchical regression was conducted with post-session confidence as the criterion variable. Pre-session confidence and number of words were entered at stage 1 to control for pre-session levels of 
confidence and the extent of the counselling session. Client characteristic variables correlated with post-session confidence $(p<.10)$ were entered at stage 2 and depth and smoothness variables at stage 3 . The variables were entered in this order as to measure session impact over and beyond what participants brought into the session. Table 3 shows the results of the regression analysis. Examination of Table 3 indicates that both depth $(p<.001)$ and smoothness $(p=.032)$ are significant predictors of change in confidence after controlling for pre-session confidence, number of words, and client characteristics.

Insert Table 3 about here

A separate three stage hierarchical multiple regression was conducted with post-session psychological distress as the criterion variable. Pre-session distress and number of words were entered at stage 1 , client characteristics variables correlated with post-session distress $(p<.10)$ were entered at stage 2 and depth and smoothness variables at stage 3. Examination of Table 4 indicates that depth was not a predictor of change in distress after controlling for pre-session distress, number of words and client characteristics $(p=.91)$. However, smoothness was a significant predictor of change in distress after controlling for pre-session distress, number of words and client characteristics $(p<.001)$.

Insert Table 4 about here

\section{Discussion}

This study provides a first examination of the outcomes of a single session of web-based counselling involving a large cohort of adult problem gamblers. The findings revealed that participants rated sessions as deep as well as smooth and present to sessions high on importance and readiness and low on confidence to resist an unexpected urge to gamble. In addition, web-based counselling was associated with an increase in confidence and a reduction in psychological distress for this sample of participants. Indeed, greater depth and smoothness was related to greater change in confidence scores as well as reduced distress, with session depth and smoothness also predicting improvement over and above client characteristics. Our results extend previous work involving single sessions delivered by telephone or face-to-face for problem gambling (Abbott et al., 2012; Hodgins, Currie, et al., 2009; Petry et al., 2008; Toneatto \& Gunaratne, 2009) and provide evidence in favour of delivering a single session online. Similar to King, Bambling, Reid, et al. (2006), clients reported improved outcomes, even though they 
received an unstructured intervention not specifically targeting these issues. This is especially relevant to our

study in so much as clients were accessing a community-based service via chat and engaged in a counselling process that was not guided by extensive assessment or a treatment manual.

Consistent with a study of clients involved in ongoing treatment delivered online (Reynolds et al., 2013) as well as single session (Cohen \& Kerr, 1998; Kuutmann \& Hilsenroth, 2012), our participants accessing a single session of web-based counselling also reported positive depth and smoothness ratings. However, in contrast to Reynolds et al., we found ratings of smoothness were higher than ratings of depth. It is unclear whether these findings relate to the nature of a brief single session of counselling, are influenced by the lack of physical, aural or oral characteristics of the modality, or a combination of both. Despite these differences, it appears that a single session of online counselling can be as deep and as smooth as face-to-face or indeed ongoing interventions delivered online.

Greater depth and smoothness of sessions were related to greater change in confidence and psychological distress. While research investigating these two dimensions has consistently found they are independent (Stiles et al., 1994; Stiles \& Snow, 1984), there is limited evidence that they differentially predict treatment outcomes beyond correlational studies and those exploring the counselling process (e.g., therapeutic alliance). The current study suggests that depth and smoothness do vary independently, and are related to differing therapeutic outcomes. In addition, the finding that smoothness predicted change in distress and that depth predicted change in confidence over and above a range of client characteristics suggests the character of the session is important to client outcomes.

These findings have implications in terms of screening, clinician training and immediate counsellor responsiveness. First, clients presented with high importance and readiness to change but low confidence to resist and urge to gambling. This suggests brief interventions that apply motivational approaches might be better suited to focus on improving self-efficacy rather than readiness to change. Indeed research investigating the content of online counselling sessions reported that sessions focused more on information gathering and less on improving self-efficacy (Rodda, Lubman, Cheetham, Dowling, \& Jackson, 2015). Second, while counsellors typically rate sessions positively when they are deep (Barak \& Bloch, 2006), our findings suggest that sessions perceived as easy and smooth were more helpful that deep and meaningful work to for distressed clients. However, while distress was not uncommon within the sample, not all clients were in crisis, and it is therefore important to understand whether assisting a client to reduce their distress is a necessary activity that must occur prior to other therapeutic activity. Third, we found clients who had both deep and smooth sessions reported greater increases in 
confidence to resist an urge to gamble, suggesting that we need to help clients and counsellors prioritise between distress reduction and confidence building when engaging in a time limited session. However, it is possible that learning to manage distress, which is often a precursor to gambling relapse, acts to increase confidence to manage an urge to gamble.

While the current study has exclusively focused on the client, previous research suggests that counsellor factors can impact on session evaluations. For example, Cummings, Slemon, and Hallberg (1993) found clients of more experienced counsellors reported greater depth as well as smoothness than those working with less experienced or novice counsellors. In addition, less experienced counsellors also rated their sessions as deeper than more experienced counsellors. This was in part explained by the focus of the counselling sessions where more experienced counsellors reflected on the development of client insight and less experienced counsellors reflected on the client emotional state and the counsellors' own performance in the session (i.e., self-critique). Indeed, online counselling requires an additional set of technical and communication skills over and above that required for traditional therapy. This includes basic technical skills such as typing proficiency and speed as lengthy delays in response time can be disengaging for both the client and counsellor (Bambling, King, Reid, \& Wegner, 2008), high verbal communication skills to avoid misunderstanding (i.e., there is no other non-verbal communication such as eye contact or smiling available) as well as time management (text reduces words spoken in an hour) and heightened skills in identifying and responding to heightened distress and risk of harm. Future research could consider including counsellor experience as well as the content of sessions as a means of further understanding the process of achieving smooth and deep sessions online.

There is good evidence that therapeutic alliance can be established in online counselling (Sucala, 2012). But there have been limited investigations of the outward behavioural indicators typically observed as measure of therapeutic alliance (e.g., smiling or sustained eye contact). In addition, there was a positive relationship between smoothness and depth and the outcome variables of confidence and distress, but it is not clear why. The current study found sessions were rated similarly smooth and deep to other modalities but further research is required to describe the character of depth and smoothness in terms of informing practice. Future research could address this issue by identifying transcripts rated with high and low depth and smoothness. Client characteristics as well as the content of the transcript could then be examined in detail to understand exactly what is contained in a deep and smooth session.

While the current study is important in providing new information on the process and outcomes of online counselling, it is not without limitations. Firstly, the outcome measures were limited to single item readiness rulers 
and research on the use of rulers as outcome measures is still developing. However, there have now been multiple

large scale studies involving non-treatment seeking samples suggesting readiness rulers are reliable and valid (Abar et al., 2012; Abar et al., 2013; Boudreaux et al., 2012). Second, our response rate was comparable with other treatment studies conducted online but there would be issues associated with generalizability. Given the non-random sampling approach it is also not possible to extend these findings to the entire population of people that access this chat based service. Nevertheless, the current study did show improvements in client distress and readiness and it would be helpful to know whether these findings are substantiated over the longer term.

Third, post-session ratings were completed immediately after talking with a counsellor. Completing ratings immediately after a counselling session is common in online research (Reynolds \& Stiles, 2007) and the Session Evaluation Questionnaire is intended for administration immediately following a counselling session (Stiles et al., 1994). However, it is possible that completing these measures immediately following a session allowed little time for reflection, integration or actions towards completing activities discussed in sessions. Further, it may be that people felt they needed to be more positive than they felt. It is not known whether these positive ratings persist beyond the timeframe of the session. In addition we did not measure the counsellor experiences of the session and given that the interaction is a joint endeavour (client-counsellor) this may be important for future studies.

Fourth, while we identified confidence to change and psychological distress as important outcome variables for a single session of online counselling for problem gambling, it is possible that there are other outcomes that could be aligned to supporting client goals (e.g., general well-being). Future research might also consider how the content of counselling sessions are aligned with these outcomes and how the content relates to session evaluations.

Although services that provide an immediate response report high rates of participation across a range of health areas (Urbis et al., 2003), it is perhaps surprising that there is limited evidence that explores the impact of providing interventions at a time when the client is experiencing the impact of their behaviour. The great majority of research into the treatment of problem gambling has been focused on clients engaged in an ongoing therapeutic program. This is despite good evidence accumulated over the past 15 years suggesting that a self-help workbook or telephone call even as brief as ten minutes can have a significant impact on problem gambling (Hodgins, Currie, \& el-Guebaly, 2001; Petry et al., 2008). The finding that a single session can impact change for gamblers is consistent with a growing literature that suggests that one session of counselling is sufficient for successful outcomes for a broad range of disorders (Talmon, 1990). Although longer term follow-up is required, the current 
study extends the available literature through the finding that a brief single session of online counselling can improve outcomes and is experienced positively by gamblers, at least in the short term. 


\section{References}

Abar, B., Baumann, B. M., Rosenbaum, C., Boyer, E., \& Boudreaux, E. D. (2012). Readiness to change alcohol and illicit drug use among a sample of emergency department patients. Journal of Substance Use, 17(3), 260-268.

Abar, B., Baumann, B. M., Rosenbaum, C., Boyer, E., Ziedonis, D., \& Boudreaux, E. D. (2013). Profiles of importance, readiness and confidence in quitting tobacco use. Journal of Substance Use, 18(2), 75-81.

Abbott, M., Bellringer, M., Vandal, A., Hodgins, D., Preez, K., Landon, J., . . Feigin, V. (2012). Effectiveness of problem gambling brief telephone interventions: A randomised controlled trial. Gambling and Addictions Research Centre, Auckland University of Technology: Prepared for: Ministry of Health, 2012.

Bambling, M., King, R., Reid, W., \& Wegner, K. (2008). Online counselling: the experience of counsellors providing synchronous single-session counselling to young people. Counselling and Psychotherapy Research, 8(2), 110-116.

Barak, A., \& Bloch, N. (2006). Factors related to perceived helpfulness in supporting highly distressed individuals through an online support chat. CyberPsychology \& Behavior, 9, 60-68.

Bewick, B. M. (2010). Providing Web-Based Feedback and Social Norms Information to Reduce Student Alcohol Intake: A Multisite Investigation. Journal of Medical Internet Research, 12(5).

Bland, J. M., \& Altman, D. G. (1994). Regression towards the mean. BMJ: British Medical Journal, 308(6942), 1499.

Blaszczynski, A., \& Nower, L. (2002). A pathways model of problem and pathological gambling. [review]. Addiction, 97, 487-499.

Bonate, P. L. (2010). Analysis of pretest-posttest designs. Florida: CRC Press.

Boudreaux, E. D., Sullivan, A., Abar, B., Bernstein, S. L., Ginde, A. A., \& Camargo Jr, C. A. (2012). Motivation rulers for smoking cessation: a prospective observational examination of construct and predictive validity. Addict Sci Clin Pract, 7(8).

Christensen, D. R., Dowling, N. A., Jackson, A. C., Brown, M., Russo, J., Francis, K. L., \& Umemoto, A. (2013). A proof of concept for using brief Dialectical Behavior Therapy as a treatment for problem gambling. Behaviour Change, 30(02), 117-137.

Cohen, G. E., \& Kerr, B. A. (1998). Computer-mediated counseling: An empirical study of a new mental health treatment. Computers in Human Services, 15(4), 13-27.

Cowlishaw, S., Merkouris, S., Dowling, N., Anderson, C., Jackson, A., \& Thomas, S. (2012). Psychological therapies for pathological and problem gambling. Cochrane Database Syst Rev, 11.

Crisp, B., Thomas, S. A., Jackson, A. C., \& Thomason, N. (2001). The influence of demographic, behavioural and treatment characteristics on problem gambling counselling outcomes. Australian Journal of Primary Health, 7(2), 32-36.

Cummings, A. L., Slemon, A. G., \& Hallberg, E. T. (1993). Session evaluation and recall of important events as a function of counselor experience. Journal of Counseling Psychology, 40(2), 156.

de Lisle, S., Dowling, N. A., \& Allen, J. S. (2014). Mechanisms of Action in the Relationship between Mindfulness and Problem Gambling Behaviour. International Journal of Mental Health and Addiction, $1-20$.

Dowling, M., \& Rickwood, D. (2013). Online counseling and therapy for mental health problems: A systematic review of individual synchronous interventions using chat. Journal of Technology in Human Services, $31(1), 1-21$.

Dowling, N., Smith, D., \& Thomas, T. (2006). Treatment of female pathological gambling: the efficacy of a cognitive-behavioural approach. Journal of Gambling Studies, 22(4), 355-372.

Dowling, N., Smith, D., \& Thomas, T. (2007). A comparison of individual and group cognitive-behavioural treatment for female pathological gambling. Behav Res Ther, 45, 2192-2202. 
Dowling, N., Smith, D., \& Thomas, T. (2009). A Preliminary Investigation of Abstinence and Controlled Gambling as Self-Selected Goals of Treatment for Female Pathological Gambling. Journal of Gambling Studies, 25(2), 201-214.

Dowling, N. A. (2013). Treatment of Female Problem Gambling. In D. Richard, A. Blaszczynski \& L. Nower (Eds.), The Wiley-Blackwell handbook of disordered gambling (pp. 225-250). West Sussex: John Wiley and Sons, Ltd.

Dowling, N. A., Cowlishaw, S., Jackson, A. C., Merkouris, S. S., Francis, K. L., \& Christensen, D. R. (in press). The prevalence of comorbid personality disorders in treatment-seeking problem gamblers: A systematic review and meta-analysis. Journal of Personality Disorders.

Dowling, N. A., Cowlishaw, S., Jackson, A. C., Merkouris, S. S., Francis, K. L., \& Christensen, D. R. (in press). The prevalence of psychiatric comorbidity in treatment-seeking problem gamblers: A systematic review and meta-analysis.

Dowling, N. A., Rodda, S. N., Lubman, D. I., \& Jackson, A. C. (2014). The impacts of problem gambling on concerned significant others accessing web-based counselling. Addictive Behaviors, 39(8), 1253-1257.

Evans, L., \& Delfabbro, P. (2005). Motivators for change and barriers to help-seeking in Australian problem gamblers. Journal of Gambling Studies, 21(2), 133-155.

Friedlander, M. L., Thibodeau, J. R., \& Ward, L. G. (1985). Discriminating the" good" from the" bad" therapy hour: A study of dyadic interaction. Psychotherapy: Theory, Research, Practice, Training, 22(3), 631.

Gainsbury, S., Hing, N., \& Suhonen, N. (2013). Professional help-seeking for gambling problems: Awareness, barriers and motivators for treatment. Journal of Gambling Studies, 1-17.

Guo, S., Manning, V., Thane, K. K. W., Ng, A., Abdin, E., \& Wong, K. E. (2012). Predictors of Treatment Outcome Among Asian Pathological Gamblers (PGs): Clinical, Behavioural, Demographic, and Treatment Process Factors. Journal of Gambling Studies, 1-15.

Hesse, M. (2006). The Readiness Ruler as a measure of readiness to change poly-drug use in drug abusers. Harm reduction journal, $3(3), 3$.

Hodgins, D. C., Ching, L., \& McEwen, J. (2009). Strength of commitment language in motivational interviewing and gambling outcomes. Psychology of addictive behaviors, 23(1), 122.

Hodgins, D. C., Currie, S., el-Guebaly, N., \& Peden, N. (2004). Brief motivational treatment for problem gambling: a 24-month follow-up. [Research; RCT]. Psychology of Addictive Behaviors 18(3), 293-296.

Hodgins, D. C., Currie, S. R., Currie, G., \& Fick, G. H. (2009). Randomized trial of brief motivational treatments for pathological gamblers: More is not necessarily better. Journal of Consulting and Clinical Psychology, 77(5), 950-960. doi: 10.1037/a0016318

Hodgins, D. C., Currie, S. R., \& el-Guebaly, N. (2001). Motivational enhancement and self-help treatments for problem gambling. Journal of Consulting and Clinical Psychology, 69(1), 50-57. doi: 10.1037//0022006x.69.1.50

Hosmer, D., W.,, \& Lemeshow, S. (1989). Applied logistic regression. New York: John Wiley and Sons.

King, R., Bambling, M., Lloyd, C., Gomurra, R., Smith, S., Reid, W., \& Wegner, K. (2006). Online counselling: The motives and experiences of young people who choose the Internet instead of face to face or telephone counselling. Counselling and Psychotherapy Research, 6(3), 169-174.

King, R., Bambling, M., Reid, W., \& Thomas, I. (2006). Telephone and online counselling for young people: A naturalistic comparison of session outcome, session impact and therapeutic allience. Counselling and Psychotherapy and Research, 6(3), 175 - 181.

King, R., Bickman, L., Shochet, I., McDermott, B., \& Bor, B. (2010). Use of the internet for provision of better counselling and psychotherapy services to young people, their families and carers. Psychotherapy in Australia, 17(1), 66-74.

Kuutmann, K., \& Hilsenroth, M. J. (2012). Exploring In- Session Focus on the Patient-Therapist Relationship: Patient Characteristics, Process and Outcome. Clinical Psychology \& Psychotherapy, 19(3), 187-202. 
Ledbetter, A. M., \& Larson, K. A. (2008). Nonverbal cues in e-mail supportive communication: Associations with sender sex, recipient sex, and support satisfaction. Information, Communication \& Society, 11(8), 1089-1110.

Ledgerwood, D. M., Arfken, C. L., Wiedemann, A., Bates, K. E., Holmes, D., \& Jones, L. (2013). Who Goes to Treatment? Predictors of Treatment Initiation among Gambling Help- Line Callers. The American Journal on Addictions, 22(1), 33-38.

Ledgerwood, D. M., Wiedemann, A. A., Moore, J., \& Arfken, C. L. (2011). Clinical characteristics and treatment readiness of male and female problem gamblers calling a state gambling helpline. Addiction Research \& Theory, 1-10. doi: 10.3109/16066359.2011.588815

Melville, K., Casey, L. M., \& Kavanagh, D. J. (2007). Psychological treatment dropout among pathological gamblers. Clinical Psychology Review, 27(8), 944-958.

Miller, J. K. (2008). Walk-in single session team therapy: A study of client satisfaction. Journal of Systemic Therapies, 27(3), 78-94.

Petry, N. M. (2005). Stages of change in treatment-seeking pathological gamblers. Journal of Consulting and Clinical Psychology, 73(2), 312.

Petry, N. M., Weinstock, J., Ledgerwood, D. M., \& Morasco, B. (2008). A randomized trial of brief interventions for problem and pathological gamblers. Journal of Consulting and Clinical Psychology, $76(2), 318$.

Postel, M. G. (2010). Effectiveness of a web-based intervention for problem drinkers and reasons for dropout: randomized controlled trial. J Med Internet Res, 12(4), e68.

Productivity Commission. (2010). Gambling (Draft Report ed., Vol. Report Number 50). Canberra.

Reynolds, D. A. J., Stiles, W. B., Bailer, A. J., \& Hughes, M. R. (2013). Impact of Exchanges and ClientTherapist Alliance in Online-Text Psychotherapy. Cyberpsychology, Behavior, and Social Networking, 16(5), 370-377.

Reynolds, D. J., Stiles, W. B., \& Grohol, J. M. (2006). An investigation of session impact and alliance in internet based psychotherapy: Primliminary results. Counselling and Psychotherapy and Research, $6(3), 164-168$

Riley, B., Smith, D., \& Oakes, J. (2011). Exposure therapy for problem gambling in rural communities: a program model and early outcomes. [Evaluation Studies]. The Australian journal of rural health, 19(3), 142-146. doi: 10.1111/j.1440-1584.2011.01199.x

Rodda, S. N., \& Lubman, D. I. (2014). Characteristics of gamblers using a national online counselling service for problem gambling. Journal of Gambling Studies, under review.

Rodda, S. N., \& Lubman, D. I. (2012). Ready to change: A scheduled telephone-counselling program for problem gambling. Australasian psychiatry, 20(4), 338-342.

Rodda, S. N., Lubman, D. I., Cheetham, A., Dowling, N. A., \& Jackson, A. C. (2015). Single session web-based counselling: a thematic analysis of content from the perspective of the client. British Journal of Guidance \& Counselling, 43(1), 117-130. doi:10.1080/03069885.2014.938609

Rodda, S. N., Lubman, D. I., Dowling, N., Bough, A., \& Jackson, A. (2013). Web-Based Counseling for Problem Gambling: Exploring Motivations and Recommendations. Journal of Medical Internet Research, 15(5).

Rodda, S. N., Lubman, D. I., Iyer, R., Gao, C., \& Dowling, N. (2015). Subtyping based on readiness and confidence: the identification of help-seeking profiles for gamblers accessing web-based counselling. Addiction, 110, 494-501.

Rodda, S. N., Lubman, D. I., Dowling, N. A., \& McCann, T. V. (2013). Reasons for using web-based counselling among family and friends impacted by problem gambling. Asian Journal of Gambling Issues and Public Health, 3(1), 1-11.

Samstag, L. W., Batchelder, S. T., Muran, J. C., Safran, J. D., \& Winston, A. (1998). Early Identification of Treatment Failures in Short-Term Psychotherapy: An Assessment of Therapeutic Alliance and Interpersonal Behavior. The Journal of Psychotherapy Practice and Research, 7(2), 126. 
Smith, S., Thomas, S., \& Jackson, A. C. (2004). An exploration of the therapeutic relationship and counselling outcomes in a problem gambling counselling service. Journal of Social Work Practice, 18(1), 99-112.

Stiles, W. B., Reynolds, S., Hardy, G., Rees, A., Barkham, M., \& Shapiro, D. (1994). Evaluation and description of psychotherapy sessions by clients using the Session Evaluation Questionnaire and the Session Impacts Scale. Journal of Counseling Psychology, 41(2), 175-185.

Stiles, W. B., \& Snow, J. S. (1984). Dimensions of psychotherapy session impact across sessions and across clients. British Journal of Clinical Psychology, 23(1), 59-63.

Sucala, M., Schnur, J. B., Constantino, M. J., Miller, S. J., Brackman, E. H., \& Montgomery, G. H. (2012). The Therapeutic Relationship in E-Therapy for Mental Health: A Systematic Review. Journal of Medical Internet Research, 14(4), e110. doi:10.2196/jmir.2084

Suurvali, H., Cordingley, J., Hodgins, D. C., \& Cunningham, J. A. (2009). Barriers to Seeking Help for Gambling Problems: A Review of the Empirical Literature. Journal of Gambling Studies, 25(3), $407-$ 424.

Thomas, S. A., Merkouris, S. S., Radermacher, H. L., Dowling, N. A., Misso, M. L., Anderson, C. J., \& Jackson, A. C. (2011). Australian guideline for treatment of problem gambling: an abridged outline. MEDICAL JOURNAL OF AUSTRALIA, 195(11), 664-665.

Toneatto, T., \& Gunaratne, M. (2009). Does the Treatment of Cognitive Distortions Improve Clinical Outcomes for Problem Gambling? Journal of Contemporary Psychotherapy, 39(4), 221-229.

Tryon, G. (1990). Session depth and smoothness in relation to the concept of engagement in counseling. Journal of Counseling Psychology, 37(3), 248.

Urbis, Keys and, \& Young. (2003). National review of tele counselling and web counselling services: Final report. Canberra: Australian Government Department of Health and Ageing.

van Wier, M. F., Ariens, G. A. M., Dekkers, J. C., Hendriksen, I. J. M., Smid, T., \& van Mechelen, W. (2009). Phone and e-mail counselling are effective for weight management in an overweight working population: a randomized controlled trial. BMC Public Health, 1-12.

Wade, N. G., Post, B. C., Cornish, M. A., Vogel, D. L., \& Tucker, J. R. (2011). Predictors of the change in selfstigma following a single session of group counseling. Journal of Counseling Psychology, 58(2), 170.

Walker, M., Toneatto, T., Potenza, M., Petry, N., Ladouceur, R., Hodgins, D. C., . . Blaszczynski, A. (2006). A framework for reporting outcomes in problem gambling treatment research: The Banff, Alberta Consensus. Addiction, 101(4), 504-511.

Wohl, M. J., \& Sztainert, T. (2011). Where did all the pathological gamblers go? Gambling symptomatology and stage of change predict attrition in longitudinal research. Journal of gambling studies, 27(1), 155169. doi: 10.1007/s10899-010-9186-0

Wood, R. T. A., \& Griffiths, M. (2007). Online guidance, advice and support for problem gamblers and concerned relatives and friends: an evaluation of the GamAid pilot service. British Journal of Guidance and Counselling, 35(4), 373-389.

Wulfert, E., Blanchard, E. B., Freidenberg, B. M., \& Martell, R. S. (2006). Retaining Pathological Gamblers in Cognitive Behavior Therapy Through Motivational Enhancement A Pilot Study. Behavior Modification, 30(3), 315-340. 
Table 1: Means, standard deviations and medians on the Session Evaluation Questionnaire for webbased counselling sessions

\begin{tabular}{llccc}
\hline & Items & Means & SD & Median \\
\hline Overall & Bad-good & 5.83 & 1.68 & 7.00 \\
& Worthless-valuable & 5.07 & 2.07 & 6.00 \\
& Shallow-deep & 4.55 & 1.53 & 5.00 \\
& Empty-full & 4.83 & 1.69 & 5.00 \\
& Weak-powerful & 4.78 & 1.57 & 5.00 \\
& Ordinary-special & 4.36 & 1.72 & 4.00 \\
& Tense-relaxed & 4.99 & 1.83 & 5.00 \\
& Unpleasant-pleasant & 5.44 & 1.63 & 6.00 \\
& Difficult-easy & 5.48 & 1.77 & 6.00 \\
& Rough-smooth & 5.12 & 1.54 & 5.00
\end{tabular}




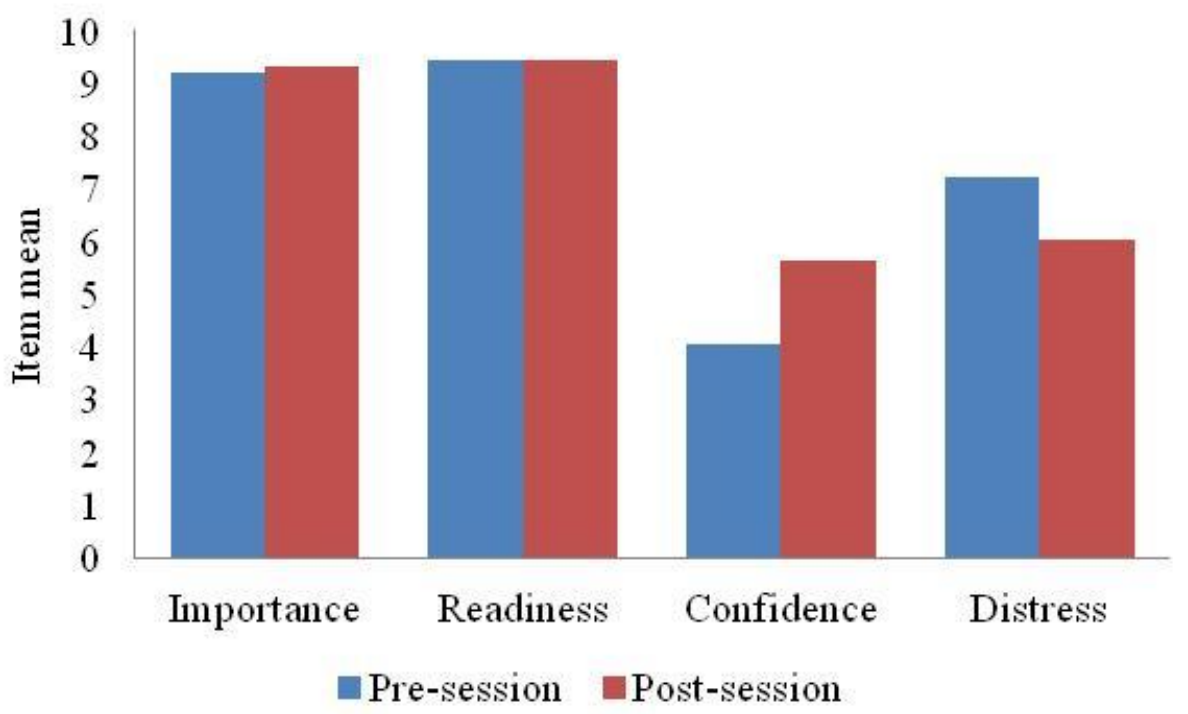

Figure 1 Mean score on readiness and distress before and following a web-based counselling session 
Table 2. Partial correlations controlling for pre-session confidence and psychological distress across session outcomes, client characteristics and session evaluation

\begin{tabular}{|c|c|c|c|c|c|c|c|c|c|}
\hline & 2 & 3 & 4 & 5 & 6 & 7 & 8 & 9 & 10 \\
\hline 1. Post-session confidence & $-.36 * *$ & $.44 * *$ & $.37 * *$ & -.12 & $-.20 * *$ & .24 & -.10 & -.04 & $-.21 * *$ \\
\hline $\begin{array}{l}\text { 2. Post-session psychological } \\
\text { distress }\end{array}$ & & $-.27 * *$ & $-.34 * *$ & -.01 & .13 & -.12 & $-.18 * *$ & .06 & $-.21 * *$ \\
\hline 3. Session depth & & & $.68 * *$ & -.01 & .02 & .08 & .05 & -.03 & $.29 * *$ \\
\hline 4. Session smoothness & & & & .01 & .06 & .09 & .11 & -.01 & $.26 * *$ \\
\hline 5. Gender $(\mathrm{F})$ & & & & & $.39 * *$ & $.43 * *$ & $.15^{*}$ & $.21 * *$ & -.04 \\
\hline 6. Age $(>35)$ & & & & & & $.19 * *$ & $.14^{*}$ & .10 & $-.17 *$ \\
\hline $\begin{array}{l}\text { 7. Preferred gambling activity } \\
\text { (non-strategic) }\end{array}$ & & & & & & & $.38 * *$ & $19 * *$ & -.03 \\
\hline $\begin{array}{l}\text { 8. Preferred mode of activity (in } \\
\text { venue) }\end{array}$ & & & & & & & & .04 & -.12 \\
\hline 9. PSGI gambling severity & & & & & & & . & & $-.14 *$ \\
\hline $\begin{array}{l}\text { 10. Preferred mode of help-seeking } \\
\text { (online help) }\end{array}$ & & & & & & & & & - \\
\hline
\end{tabular}

**. Correlation is significant at the 0.01 level (2-tailed).

*. Correlation is significant at the 0.05 level (2-tailed). 
Table 3. Summary of Hierarchical Regression Analysis for Variables Predicting Post-Session Confidence $(N=229)$

\begin{tabular}{|c|c|c|c|c|c|c|c|c|c|}
\hline \multirow[b]{2}{*}{ Variable } & \multicolumn{3}{|c|}{ Model 1} & \multicolumn{3}{|c|}{ Model 2} & \multicolumn{3}{|c|}{ Model 3} \\
\hline & $B$ & $S E B$ & $\beta$ & $B$ & $S E B$ & $\beta$ & $B$ & $S E B$ & $\beta$ \\
\hline Pre-session confidence & .63 & .06 & $.59 * *$ & .58 & .06 & $.54 * *$ & .53 & .05 & $.49 * *$ \\
\hline Number of words & .00 & .00 & $.11 *$ & .01 & .01 & .09 & .00 & .00 & .05 \\
\hline Gender $(F)$ & & & & -.48 & .34 & -.08 & -.40 & .30 & -.07 \\
\hline Age $(>35)$ & & & & -.62 & .33 & $-.11 * *$ & -.84 & .30 & $-.15^{* *}$ \\
\hline $\begin{array}{l}\text { Preferred mode of help-seeking } \\
\text { (online) }\end{array}$ & & & & .17 & .06 & $.14^{* *}$ & .04 & .06 & .04 \\
\hline Session depth & & & & & & & .50 & .14 & $.25 * *$ \\
\hline Session smoothness & & & & & & & .30 & .14 & $.14^{*}$ \\
\hline Adjusted $R^{2}$ change & & .36 & & & .05 & & & .12 & \\
\hline$F$ for change in $R^{2}$ & & $60.51 * *$ & & & $6.08 * *$ & & & $25.51 * *$ & \\
\hline
\end{tabular}

**. Correlation is significant at the 0.01 level (2-tailed).

*. Correlation is significant at the 0.05 level (2-tailed). 
Table 4. Summary of Hierarchical Regression Analysis for Variables Predicting Post-Session Psychological Distress (N = 229)

\begin{tabular}{|c|c|c|c|c|c|c|c|c|c|}
\hline \multirow[b]{2}{*}{ Variable } & \multicolumn{3}{|l|}{ Model 1} & \multicolumn{3}{|l|}{ Model 2} & \multicolumn{3}{|c|}{ odel 3} \\
\hline & $B$ & $S E B$ & $\beta$ & $B$ & $S E B$ & $\beta$ & $B$ & $S E B$ & $\beta$ \\
\hline $\begin{array}{l}\text { Pre-session psychological } \\
\text { distress }\end{array}$ & .67 & .06 & $-.50 * *$ & .65 & .06 & $.58 * *$ & .62 & .06 & $.56^{* *}$ \\
\hline Number of words & -.01 & .00 & $-.11 *$ & -.01 & -.00 & -.10 & .00 & .00 & -.08 \\
\hline Age $(>35)$ & & & & .64 & .32 & $.11 *$ & .77 & .31 & $.13^{*}$ \\
\hline $\begin{array}{l}\text { Preferred gambling activity } \\
\text { (non-strategic) }\end{array}$ & & & & -.37 & .35 & -.06 & -.30 & .35 & -.05 \\
\hline $\begin{array}{l}\text { Preferred mode of gambling } \\
\text { (in venue) }\end{array}$ & & & & -1.2 & .41 & $-.16^{* *}$ & -.93 & .39 & $-.13^{*}$ \\
\hline $\begin{array}{l}\text { Help-seeking preference } \\
\text { (online help) }\end{array}$ & & & & -.19 & .07 & $-.16^{* *}$ & -.11 & .07 & -.09 \\
\hline Session depth & & & & & & & -.02 & .15 & -.01 \\
\hline Session smoothness & & & & & & & -.51 & .15 & $-.23 * *$ \\
\hline Adjusted $R^{2}$ change & & .37 & & & .06 & & & .05 & \\
\hline$F$ for change in $R^{2}$ & & $64.81 * *$ & & & $5.89 * *$ & & & $10.41 * *$ & \\
\hline
\end{tabular}

**. Correlation is significant at the 0.01 level (2-tailed).

*. Correlation is significant at the 0.05 level (2-tailed). 
Web-based intervention for problem gambling 24 